\title{
The window of soil iron redox activity across the time-climate pedogenic matrix of the Hawaiian Islands
}

\author{
AARON THOMPSON ${ }^{1}$, CAITLIN HODGES $^{2}$, AND OLIVER \\ CHADWICK $^{3}$
}

${ }^{1}$ Univ of Georgia, Athens GA, USA, AaronT@uga.edu

${ }^{2}$ Penn State Univ, Univ Park, PA, USA, cah423@psu.edu

${ }^{3}$ Univ of California, Santa Barbara, CA, USA, oac@geog.ucsb.edu

In upland soils, the changes and transformations of soil iron $(\mathrm{Fe})$ over the course of pedogenesis dictate Fe's role in ecosystem biogeochemistry. Since redox transformations of $\mathrm{Fe}$ accentuate its impact on ecosystem processes, we asked what are the climatic and pedogenic conditions that poise soils for active iron redox cycling? Along a series of climate $(610 \mathrm{~mm}$ to $4000 \mathrm{~mm}$ MAP) and age (0.3 ky to 4,100 ky) gradients, we (a) examined iron mineral composition using Mössbauer spectroscopy and quantified the potential for Fe reduction using passive redox probes (Steel IRIS probes). We hypothesized that the potential $\mathrm{Fe}$ reduction would increase with mean annual precipitation, a proxy for soil moisture, and would be highest at intermediate aged sites (i.e., $120 \mathrm{ky}$ ), where we also anticipated the peak in abundance of shortrange-ordered (SRO) Fe minerals. We found significant basaltic glass can persist for $10 \mathrm{ky}$ in the driest rainfall soils, but $>1200 \mathrm{~mm}$ MAP, oxidized Fe minerals dominate. We find SRO Fe mineral abundance reaches a maximum in the sites of intermediate rainfall and age, as shown previously, but we also found that SRO Fe minerals persist in low abundance to the oldest sites at low and intermediate rainfall, whereas at the highest rainfall, oxidized $\mathrm{Fe}$ minerals are replaced by $\mathrm{Fe}$ in organic complexes and silicates before $350 \mathrm{ky}$. The potential for Fe reduction increased linearly with mean annual precipitation across all sites $(\mathrm{p}<0.001)$, with no effect of soil age $(p=0.73)$. However, when taking into account the native Fe pools across the gradients, we predict that $\mathrm{Fe}$ reduction is an active force driving soil processes of an increasingly smaller climatic range as soil age increases (from 2000-4000+ mm MAP at 0.3 $\mathrm{ky}$, to 2000-2500 mm MAP at $4100 \mathrm{ky}$ ). The timeclimate window of active Fe redox cycling thus shrinks with pedogenic age and demarcates soil conditions where $\mathrm{Fe}$ minerals play a pivotal role in the nutrient and carbon cycles of these Hawaiian soils. 